\title{
Labor control and task autonomy under the sharing economy: a mixed-method study of drivers' work
}

\author{
Qingjun $\mathrm{Wu}^{1^{*}}$ (D) and Zhen $\mathrm{Li}^{2}$
}

\footnotetext{
* Correspondence: wqjruc@163.com ${ }^{1}$ School of Labor and Human Resources, Renmin University of China, No. 59 Zhongguancun Street, Haidian District, Beijing 100872, People's Republic of China Full list of author information is available at the end of the article
}

\begin{abstract}
This mixed-method study analyzes the labor process and labor supply of drivers on a Chinese mobile-travel platform. Different from the control of the traditional labor process, such platforms have a more-fragmented control of labor, which coexists with workers' task autonomy. Based on this assessment, we propose three core mechanisms by which platforms control the labor process and produce work consent: task autonomy, performance-related pay and motivation, and the star rating system. Under the influence of these three mechanisms, workers form both active consent to and passive acceptance of the platform and its rules. Moreover, we analyze data from a survey of 15,484 drivers to show that drivers' work consent could be transformed into overwork, although identity difference is at play in the transformation process.
\end{abstract}

Keywords: Sharing economy, Labor process, Labor supply, Task autonomy, Work consent

\section{Introduction}

Since the birth of Uber in 2010, the sharing economy's employment model has drawn wide attention and fierce debate from various parts of society. In academia, the debates have focused either on setting the rules of competition between the sharing economy and traditional business models, ${ }^{1}$ or on whether the workers (in this case the drivers) on the platform are employees. Among the many criteria to decide the existence of such employment relations, the most essential is whether or not workers accept and follow orders from the platform during their labor process, and if they do how long this obedience lasts (Cappelli and Keller 2013; Cunningham-Parmeter 2016; Brown 2016). ${ }^{2}$ Not only is this topic still intensively debated, but different nations have also had different court rulings on related cases. Despite ongoing academic, policy, and legal debates, sharing economy platforms have sprung up since Uber was established. These include short-term rental platforms such as Airbnb, food-delivering platforms such as Meituan and Dianping, work-outsourcing platforms such as Amazon's Mechanical Turk, and many others. Numerous people are attracted by the flexibility and elasticity that these sharing economy platforms provide, resulting in a sharp increase in the number of participating workers (Katz and Krueger 2016; Harris and Krueger

(c) The Author(s). 2019 Open Access This article is distributed under the terms of the Creative Commons Attribution 4.0 International License (http://creativecommons.org/licenses/by/4.0/), which permits unrestricted use, distribution, and reproduction in any medium, provided you give appropriate credit to the original author(s) and the source, provide a link to the Creative Commons license, and indicate if changes were made. 
2015; Hall and Krueger 2018; Farrell and Greig 2016), and the penetration of this employment model into many other industries.

This paper does not analyze the existence of such employment relations. Instead, we aim to introduce the sociological theory of labor process to understand and explain the relation between sharing economy platforms and their workers. Because the essential issue in deciding this relation is control over the labor process, this paper uses laborprocess theory to analyze three major questions. First, how do online platforms supervise and control the labor process of workers? Second, what is the workers' attitude and realization about this control and supervision? Third, how does this attitude and realization of the workers affect labor supply?

To answer these questions, we study a Chinese mobile-travel platform (hereafter referred to as "Platform W"), especially its labor process and mechanisms of supervision and control. As for research method, considering that most studies on sharing economy platforms and their workers are still at the exploratory stage, we use a mixedmethod approach that includes case study and data analysis on the work of the drivers. We first conduct a case study on Platform W's rules and management as well as the work consent of its participating workers, and then carry out a quantitative analysis on a survey of 15,484 drivers.

\section{Controlling the labor process: from the industrial age to the internet era}

The study of the labor process can be traced all the way back to Karl Marx's analysis of labor. In the first volume of The Capital, Marx explains basic concepts and analytical frameworks regarding the labor process. He argues that the labor process is a purposeful activity by which workers produce used value and capitalists consume the labor force (Marx 2004). To produce added value, capitalists manage, supervise, and direct workers, and thereby exploit as much surplus value as possible through the control of the labor process. As such, through the analysis of the capitalist mode of production and organization of labor, Marx reveals the subjection of workers to capital, the capitalist exploitation of workers, and the need for workers to resist and struggle.

More than a hundred years after the publication of The Capital, study of the labor process had not received as much attention as it should. Specifically, Marxist scholars have not reached considerable theoretical breakthrough on this topic (Braverman 1974) until Braverman's (1974) book Labor and Monopoly Capital, which focuses on the scientific management of labor and the degeneration of labor skills. This book revived research on the labor process, inducing wide and long-lasting discussion around Braverman's study, including critiques from multiple angles (Elger 1979; Friedman 1977; Edwards 1981). Specifically, some scholars questioned him for ignoring workers' consciousness. ${ }^{3}$ From then on, scholars such as Friedman, Edwards, and Burawoy began to shift the focus to workers' agency, such as Burawoy's Manufacturing Consent. Burawoy centers his analysis on the labor process, investigates workers' agency and behaviors on the manufacturing level, and explains the process by which workers' awareness of "consent" is produced (Burawoy, 1979). This research extended the Marxist understanding of the capitalist labor process (see You 2006). However, some research like that of Friedman or Burawoy only explores labor and employment in the era of industrial mass production. The labor process, labor control, and worker agency that they investigate are all based on the employment relation between capital and 
labor. Recent advancement of Internet technology and socioeconomic development have generated new forms of economic activities and labor groups, and changed traditional organizational and employment relations. With this backdrop, despite the change in capital-labor relations, we should not ignore how capital asserts management and control over the labor process through Internet technology.

Sharing economy platforms and traditional employment organizations differ tremendously in terms of controlling the labor process. Most importantly, sharing economy platforms only supervise and control the process by with workers finish their tasks, and let go of all other times. This means that the workers who pick up and finish online orders can decide for themselves when and where to work, to rest, or to take a vacation. They can even decide their labor supply and salary. In short, they have task autonomy. How then can we understand the relation between platforms' control over labor and workers' work flexibility? Some valuable, albeit tentative, studies have been carried out regarding the case of Uber.

One stream of scholars who have analyzed this relationship maintain that these workers obtain task autonomy at the expense of the protection of their labor rights. They argue that the sharing economy platform weakens workers' capacity to engage in collective action and change the working environment, while requiring them to bear the uncertainty of the platform's changing prices or tightening control (Cockayne 2016) . These risks are considered a necessary trade-off for workers to obtain flexibility, such as nonfixed working hours and the ability to choose whether or not to work (Harris and Krueger 2015). Other scholars argue that even the autonomy and flexibility in time arrangement, acquired at the expense of protection, are superficial since competition increasingly lowers their wage rate. To ensure a survival for themselves and their family, workers still have to work long hours and sacrifice that autonomy and flexibility (Finkin 2016; Stanford 2017).

Other studies focus on the result of work freedom, asserting that while workers obtain autonomy, they have subjected themselves to more-stringent control by capital. Some scholars argue that since the main criterion for income and internal ranking is the time a worker continuously works on a platform, the worker has to increase his/her working time to increase their income. Workers do not have actual freedom when working for the platform, and the so-called flexibility is merely a comfort (Aloisi 2016). Ultimately, only one or two platforms can survive market competition, and power is concentrated into the hands of very few owners, making them virtual monopoly capitalists (Kenney and Zysman 2016). Under these conditions the rich get richer and their wealth is transformed to power, whereas the workers lose their income and wealth along with worker protection and decent working conditions, and the power imbalance between capital and labor worsens (Stone 2017). For those participating workers who rely on the platform for their main source of income, the platforms have even more control over their labor (Rosenblat and Stark 2016), and changes in platform policies such as decreased income and deteriorating working conditions have an even-stronger effect on them, pushing them to bear more risks and difficult working conditions (Rosenblat 2016). The Internet-based sharing economy, despite sounding generous, is in fact "a nice way for rapacious capitalists to monetize the desperation of people in the post-crisis economy" (Henwood 2015). Its flourishing has produced a new form of digital sweatshop (Aytes 2013), a twenty-firstcentury exploitation (Ettlinger 2016) that is more covert (Cao and Zhang 2012). 
When surveying the existing literature, it becomes clear that sharing economy platforms have changed the control of the labor process through Internet technology and new forms of employment. Platforms only control the process in which workers finish their tasks, but leave the rest of the day to the workers themselves. At the same time, workers enjoy a certain level of task autonomy in that they are able to freely choose when and where to work. As such, in the employment model of the sharing economy, the platforms' control over the labor process and the worker's task autonomy coexist. In the following, we use a case to analyze this new form of employment in detail and the platforms'strategic control over the labor process.

\section{The labor process and control mechanism of Platform W}

To investigate the labor control of sharing economy platforms, we chose Platform W, a mobile-travel platform, for deeper exploration. Platform W entered the online carhailing industry in 2014, and has rapidly expanded its business into a number of cities including Shanghai, Guangzhou, Shenzhen, Beijing, Chengdu, Chongqing, and Hangzhou. It has attracted numerous customers, with the last count showing 48.9 million registered users at the end of April 2016. We use Platform W for our case study because of its representativeness of the employment model and labor control strategies of the present sharing economy.

\section{"Flexible" and "autonomous" work on the platform}

Between May 2016 and April 2017, we interviewed the management of Platform W, as well as ride-hailing drivers in Beijing, Chengdu, Quanzhou, and Shenzhen. Combining the interviews and the platform's setting, we sorted out the drivers' working process. By briefly describing the labor process, we can compare the difference between working on platforms and traditional employment. Unlike traditional employment, drivers do not go through a complicated labor process such as interviews, orientation, signing a contract, training, task designation, work cooperation, performance evaluation, and salary distribution. Instead, only two processes are involved in working on the platform-namely, registration and order completion.

The first labor process, registration, can be entirely completed online. A few working days after registering, drivers receive certification from the platform. In the registration process, a driver must provide information including name, identification documents, model and make of their car, driver's license, insurance, and bank account to receive payment. After uploading this information, the driver is required to watch a short video that introduces the company, how to use the app, the process of getting an order, and important things to remember. At the end of the video, the driver is tested on these matters. Once they are through the platform's assessment and background evaluation, the driver can activate the app and formally become a ride-hailing driver.

The second labor process consists of receiving an order and completing the task. Each order is completed by the following process. First, the driver opens the app on their smartphone and clicks "go online." The platform then assigns an order to the driver based on their distance to the customer, their rating, and the like. The driver has $15 \mathrm{~s}$ to accept the order by clicking on their screen. They then call the customer to determine the pick-up spot. When the customer is picked up, the driver swipes the 
screen to start the trip, and clicks on "end trip" when he/she has arrived at the customer's destination. The driver then gives a review to the customer while the app automatically calculates the fee. This marks the end of this order, and the driver begins the wait for the next order.

The process described above means that the completion of each order is in fact a virtual production line. The driver is guided by their smartphone app to finish each task on this list-accepting the order, calling to confirm the pick-up spot, driving and finishing the trip, and reviewing. In this case, drivers, subconsciously, do not recognize this as exactly "work." "It's interesting," and "Just follow the app" are common reactions from the drivers. They finish their tasks and are paid only by "touching the screen and tapping on the pedal."

At the same time, drivers' working time seems very flexible. For example, a driver can choose when to go online based on their own schedule, how long to stay online, and when to go offline. More importantly, unlike traditional employment, the means of production, i.e., the car used for the car-hailing service, is provided by the driver. In interviews, drivers also expressed the feeling that they are "working for myself." The promotion slogan of Platform W reinforces this awareness of "flexibility" by claiming "You can be your own boss, you decide when and how long to work."

Working time and tasks on Platform W are fragmented in nature. Tasks can be completed in leisure time, while the use of computer algorithms and the app greatly increase the efficiency of matching supply to demand. Drivers therefore do not feel like controlled. Platform W uses the apparent freedom, flexibility, and autonomy of working time to attract drivers and produce the feeling that they are working freely. Compared to working under employment contracts, drivers on Platform W feel that they have more autonomy.

\section{Payment and reward system}

Through a backstage big data algorithm, Platform W has designed policies on fees and rewards that are distinct from the traditional taxi industry. The platform enjoys the power to unilaterally decide the price level and adjust it ad hoc according to traffic and weather conditions. As such, in the designing and implementation of payment and reward policies, Platform W takes the role of the rule maker.

For the purpose of service differentiation, Platform W designs different fees based on car types. For instance, from September 15, 2016 to April 2017, based on the then market competition situation, Platform $\mathrm{W}$ raised the per-kilometer fee of on-demand cars-the cheapest option on the platform-from 1.5 RMB to $1.8 \mathrm{RMB}$, and the perminute time fee from $0.25 \mathrm{RMB}$ to $0.35 \mathrm{RMB}$, while maintaining the fees for longdistance and night trips. Table 1 presents the fees after this adjustment.

According to these calculations, drivers receive the baseline fee of each order. Other than this, the platform has various rewarding practices that differ from city to city and week to week. Taking the rules of rewards in Beijing during a certain period as an example, they include:

1. Simple multiplying. For any trip in off-peak hours, the driver receives $50 \%$ of the baseline fee (including the premium) as reward, up to 70 RMB per order. 
Table 1 Fees of car-hailing service on Platform W

\begin{tabular}{llll}
\hline Basic fee standards & & & \\
\hline Car type & Level I cars & Level II cars & Level III cars \\
\hline Starting price (RMB) & 0 & 15 & 18 \\
Lowest price (RMB) & 10 & 20 & 30 \\
Distance price (RMB/km) & 1.8 & 2.3 & 3.85 \\
Time price (RMB/minute) & 0.35 & 0.4 & 0.7 \\
Long-distance trip price & $0.8 \mathrm{RMB}$ for each extra km after & $1.2 \mathrm{RMB}$ for each & $1.9 \mathrm{RMB}$ for each \\
& $12 \mathrm{~km}$ & extra km after $15 \mathrm{~km}$ extra $\mathrm{km}$ after $15 \mathrm{~km}$ \\
$\begin{array}{l}\text { Night (23:00-5:00) trip price } \\
\text { (RMB/km) }\end{array}$ & 2.2 & 3 & 5.75 \\
\hline
\end{tabular}

Source: Platform W internal website

2. Peak hour backup. On the premise that for every hour during the recognized peak hours the driver is online at least $45 \mathrm{~min}$ and completes at least one order, if the baseline fee and rewards are less than the backup amount the platform will supplement the difference.

3. Extra rewards for outstanding drivers. If in 1 week the driver completes $60 \%$ of assigned orders, completes more than 80 orders, and is rated 4.8 or higher, the platform will reward them with an extra $80 \%$ of the baseline fee of that week, up to 2000 RMB.

4. "Gold-medal" service. If in 1 week the driver is rated 4.8 or higher, completes $60 \%$ of assigned orders, and ranks in the top 100 in terms of number of orders completed, they receive an extra 400 RMB for "gold-medal service."

5. New driver's first-week reward: If the driver completes five orders within the first 7 days after activating their account, they receive 200 RMB. They receive 500 RMB if they complete ten orders within those 7 days, and 800 RMB if they complete 15 orders.

In essence, drivers' income on the platform is a transformation of their labor value or price. Platform W uses a payment system resembling a combination of hourly wage and piecemeal wage to calculate its drivers' income. This system strongly encourages drivers, and draws them into an "interesting" game through changing the reward rules for different times, periods, and regions.

\section{An invisible "employer" and management: the rating system at the core}

Upon the completion of each order, the platform encourages passengers to rate their ride experience on a scale from one to five stars. To increase information transparency and equalize information from both sides, the platform provides a mutual rating, i.e., both the driver and the passenger are able to rate each other. This mutual rating mechanism seems fair, but actually puts the driver at a disadvantage since a customer's rating does not have a meaningful effect on their travel, while the customer's rating of the driver directly impacts the latter's income. Through the rating system, the platform controls its drivers' work.

First, the rating system regulates the way drivers complete the job as well as their working conditions. All rewards that the platform offers are related to the driver's rating and completion rate of assigned orders, while the completion rate is to some degree 
affected by the rating-a lower star rating is more likely to prompt the customer to cancel the order. As such, a driver's rating directly decides if they can receive rewards, and thereby decides their actual income. To land rewards, drivers show a strong preference for higher star ratings that hence leads to a series of performances in the labor process, such as providing napkins, bottled water, and chargers to passengers; or talking to passengers in an accommodating, friendly, and positive manner. Moreover, the power to decide the driver's working conditions is partially transferred into the hands of the passenger, such as demanding that a certain type of music be played or whether the air conditioner is turned on or not.

Second, drivers' working time is influenced by the rating system. Customers see the average rating of a driver from their most recent 500 orders. When a driver has a lower star rating, they often accept more orders in the hope of improving their rating. For example, the negative impact of a one-star rating can only be counteracted by five fivestar ratings. Whether or not a driver is qualified for the weekly rewards also depends on the star rating and order-completion rate in the week, meaning that drivers are constantly being evaluated. Through this rating system, the platform stimulates drivers to work hard every week.

Third, the platform sanctions its drivers with the rating system. When a driver's rating is lower than a certain number, they cannot receive corresponding rewards and subsidies. If the rating continues to decrease, the driver's account is suspended. Edward Chen sees this mechanism as an effective way in which the platform asserts control over workers (Chen 2015). Other scholars argue that this behavior is the platform's exercising of the employer's right to dismiss (Aloisi 2016).

Fourth, the rating system implies a transfer of regulatory and managerial power, as well as of conflict. On the surface, drivers are rated by passengers based on the latter's ride experience. In fact, however, this rating system allows the platform to transfer regulatory and managerial power to customers through the app. Because of this transfer, drivers do not feel supervised or regulated by the platform. At the same time, passengers, as the customers, are naturally attuned to drivers' service, making supervision ever present during the drivers' labor process and extremely cheap. Moreover, both subjective problems, such as a driver's unfamiliarity with the route, and objective problems, such as GPS inaccuracy, can lead to bad ratings that are consequential to the driver. As soon as a passenger gives a bad rating, the driver first complains about the passenger being "too picky" or "vicious." The possibility that drivers question the rating system or the platform's control is small. At a very low cost, the platform achieves supervision of the entire working process of its drivers and silently transfers the conflict between itself and the drivers to between the customers and drivers.

Fifth, the exclusivity and nontransferability of the ratings render drivers reliant on the platform. A driver's rating on a certain platform is only valid on that platform and cannot be transferred to any other mobile travel app. Accepting orders from another platform means an end of the driver's "professional career" (Prassel and Risak 2016). Ratings, much like income, are part of a driver's "assets" on the platform, which they will not easily give up. Especially for those drivers who have already invested a great deal of energy and scored high in ratings, the nontransferability of their ratings is even more influential to their autonomy of choice. 
In addition to the rating system, the platform also supervises the drivers' labor process through other means. For example, during the registration process, drivers are asked to not accept orders from other platforms at the same time; otherwise, the platform has the right to terminate cooperation with the driver. However, the rating system is always at the center of the platform's labor-process control. The system transfers to customers the power to supervise drivers' labor process, making the platform the "invisible employer" behind the scene, and constituting a hidden control of work. Ratings are closely related to each driver's income and reputation, thereby asserting de facto control on the way, the form, and the attitude in which the driver finishes their work.

The above discussion describes the labor process of online car-hailing drivers. From this picture, we realize that drivers working on Internet platforms enjoy a certain level of work autonomy, but at the same time the platforms hold control over the drivers' labor process. Drivers thus have to accept platforms' orders, as well as the supervision and control of the process and outcome of their labor. Platforms' control and workers' autonomy simultaneously coexist in the labor process, a fundamental difference from the labor process under the traditional employment model.

\section{Work autonomy and labor identity}

Burawoy brought workers' agency into the analysis of the labor process, asserting that study of the labor process should investigate workers' experience, i.e., workers' consent to being exploited. Through his study of the "making out" game in a capitalist factory, Burawoy concluded that the game was an ideological mechanism that manufactured consent to being exploited among workers, and thereby enabled capital to acquire surplus value while masking its importance (Wen and Zhou 2007). In Burawoy's analysis, although workers developed a subjective consent during the making out game, capital still tightly controlled the labor process. Such control was no different from Braverman's idea of the detachment of "execution" from "concept."

However, under the sharing economy employment model, the way in which capital controls the labor process has changed tremendously. Using computer technology, Internet platforms divide the whole production and service task into separate work tasks that can be completed by individual workers. Just as in the labor process of Platform W, analyzed above, the platform turns the entire operation into separate orders that are tasks to be completed by individual drivers. The platform controls only the part of drivers' time when they are online and performing labor, but not any other time. Under a sharing economy model like Platform W's, control is fragmented or even totally absent if the worker does not accept orders. Therefore, the worker's perception of his/her work autonomy is not only their subjective realization, but coexists with the

platform's control. What kind of subjective experience and feeling will workers develop under this fragmented control over their labor process?

\section{Active approval of "consent"}

By advertising the autonomy and flexibility of the work and providing a promotional payment system, Platform W greatly stimulates drivers' incentive to work, and has led the drivers to approve of its rules. As such, drivers' realization and feelings regarding their work have noticeably changed because of Internet technology and innovative 
business model ( $\mathrm{Li}$ and Wang 2016). In our interviews with the drivers, we found that they are not only aware of the platform's supervision and regulation but also of the freedom and flexibility of their work. Therefore in the labor process that integrates platforms' supervision and drivers' work autonomy, drivers have developed something that resembles Burawoy's "consent," which is reflected in the following aspects.

First, drivers identify with their work autonomy and flexibility. By designing attractive promotional policies and embedding each work task into the "game," the platform has encouraged its drivers to complete "the production" and not feel bored. Instead, they see the work as interesting and feel encouraged, and therefore comply better with the platform's rules and "produce" enough or even more than what is needed to receive rewards. At the same time, there is significant differentiation among drivers regarding the reasons for participating in the platform. Some drivers work as full-time car-hailing drivers, motivated by the economic income this job gives them; others drive for social purposes or to kill time while "having a passenger share the gas cost"; yet others do it simply for fun or to join the sharing economy trend. Whatever the driver's need, the platform can fulfill it. The reason the platform can fulfill the needs of different people is that it assigns tasks through "orders." Drivers can choose to enter the platform at any time in any place; this flexibility in arranging work is the most distinctive feature of their work. Although drivers do feel the physical or mental exhaustion of discomfort during such a flexible labor process, we found most drivers in the interviews felt "relatively satisfied" with working on the platform. For instance, for drivers who do not have other skills and cannot find better employment than driving, working on the platform temporarily eases the pressure and anxiety associated with losing their job or constantly looking for employment. Some drivers who used to drive unlicensed taxis became car-hailing drivers because they "no longer have to hide." For drivers who have abundant leisure time, it is better to earn some extra income on a platform that they can choose to enter or quit at any time compared to staying at home and not getting paid. Regardless of the different motives that push drivers to the platform, this relative satisfaction helps them to actively approve of the platform's rules.

Second, drivers identify with the transparency of Internet rules regarding transactions between customers and drivers; this transparency, including that of transaction rules and of the payment system, attracts drivers to work for them. Transparent rules lower transaction costs and raise mutual trust. The drivers care most about the transparency and publicity of the payment system, including both the baseline rates and the rewards. Despite some drivers' frustration that they "don't understand how this money is calculated," transparent rules foster a sense of fairness among drivers. Moreover, to incentivize customers to hail more rides and attract more drivers to come online for orders, at its beginning stage the platform subsidizes heavily. Drivers are aware of the rapid increase in their income. On top of this, the platform calculates driver's income on a weekly basis, which means drivers actually see the change in their income. All these elements together result in drivers actively and quickly developing approval of the platform's rules or, in Burawoy's words, "unable to question the rule of the game while still participating in it" $(2008,82)$. This is a reliable foundation for workers' identification with the platform.

Third, drivers identify with the platform's promotional mechanism. Drivers are integrated into the working game designed by the platform and finish their target easily. 
Whereas the basic distance price and time price on the platform resemble the price calculation of traditional taxis, the former uses various rewarding rules to stimulate drivers' online duration and number of accepted orders. To receive these rewards, drivers intentionally lengthen their working time and accept as many orders as possible. Whereas traditional taxi drivers are preoccupied with "breaking even with today's franchise fee," their counterparts on online car-hailing platforms are preoccupied with "getting today's order amount." Also different from traditional encouragements, platforms can change the reward rules at any time. When rewards are diverse and high in value, drivers prefer short trips to, in their words, "get enough orders to secure the subsidy." To finish more tasks, drivers are prompted to put in more labor without realizing it, while changing the rules makes the game more interesting. Drivers' work is thereby integrated into the rules that the platform has designated.

According to Burawoy, although capital actually controls the entire labor process under industrial manufacturing, the making out game manufactures workers' consent to their own exploitation (Burawoy 2008). In the labor process of the sharing economy, however, capital's control over labor becomes fragmented, and platforms' control and workers' autonomy simultaneously coexist. In this backdrop, the identification that online car-hailing drivers' have developed with the Internet platform and its working rules that we see is an even-stronger subjective experience than Burawoy's consent.

\section{Passive acceptance of "consent"}

Burawoy argues that capital manufactures workers' "consent" through the capitalist factory ideology, but does not analyze whether this consent is actively developed in the workers themselves or passively formed by capital's enormous power. What we have found here is that workers do actively identify with the Internet platform and its working rules, but at the same time this subjective identification also stems from a passive acceptance resulting from the power imbalance between labor and capital.

Not all drivers are satisfied with working on the platform. As the market demand becomes saturated and the platform reduces rewards, some drivers gradually become unhappy. Some have started questioning the rules set by the platform: "At 20 percent, the platform's management fee is too high. Based on the current income, this is even higher a proportion than the franchise fee of taxi drivers." Others feel their working hours increasing, and claim that "[the work] is too binding. I can't get off the car once I get on it in the morning. I have to keep driving. Now that taxis have become active in peak hours, I can't earn money if I don't drive." Yet others have deeply felt the impact of the rating system: "I didn't have this high of a score before. Some passengers just give out one star without reason. I have no choice but to pull the rating up order -by order." Although such pressures are starting to be felt, drivers still generally accept the rules since "this platform only provides information for customers and for us. It is generally satisfying, although it could give more rewards." Despite the existence of actual grievances, most drivers deal with their dissatisfactions by continuing to work hard after expressing concerns, increasing working hours and service quality, and asking for good ratings from passengers. As Burawoy points out, "Existing grievances are not directed at fighting capitalism but at its reproduction" $(2008,102)$. Regarding drivers' recognition of the platform's rules, our analysis shows that active approval and passive acceptance coexist, and the reasons include the following. 
First, the drivers' labor is still attached to the Internet platform. Per the platform's advertisement, drivers are individual contractors who own their own assets (their cars), exercise self-management, and are not bound by the platform in any way. However, study of the drivers' labor process has found that both the drivers and their labor are still reliant on the platform. Consumers receive service through a smartphone app, their orders are accepted within seconds, and the drivers demand to pick them up at the required spot within the required time period. This model gradually results in customers' expecting the same level of accuracy from the drivers as from their technical devices, and drivers becoming the extension of the platform and the app in reality. At the same time, car hailing does not require a very high driving skill, which means drivers are easily substitutable and therefore face fierce competition. As a result, the platform and its customers see car-hailing drivers as the same kind of cheap labor as taxi drivers, and their labor increasingly commodified. Although drivers provide their own means of production, their labor belongs to the platform.

Second, workers are increasingly atomized. By introducing individual competition and conflict transfer, drivers on the platform are gradually separated into atomized individuals. In particular, part-time drivers lack a relationship with their "coworkers." Full-time car-hailing drivers share some background and experience and have WeChat group chats, but informal organizations like these are unlikely to develop solidarity for a common purpose. As competition among platforms intensifies, only one or two of the most influential platforms are likely to survive to the end, further worsening the power imbalance between labor and capital. Drivers will become increasingly powerless and only able to passively accept the platform's rules.

To summarize, by advertising "flexible and autonomous" work, Platform W has attracted numerous workers who used to be freelancers or who had ample leisure time in the traditional labor market. Once they become drivers on Platform W, the platform attains de facto control over their labor process through an attractive and interesting payment mechanism and the ad hoc rating system. This control has penetrated into various aspects of drivers' work, including environment, mode, and duration, promoting both active and passive identification with the platform's rules, and finally resulting in drivers' cooperation with the platform.

\section{Work identity in the sharing economy}

In order to better discuss work identity in the sharing economy, this section briefly summarizes the previous research. The existing literature on workers' agency in the sharing economy includes analyses from the view of the labor process. This line of work proceeds in one of two ways. The first extends Burawoy's argument by asserting that because work on platforms is made possible by virtual Internet and smartphone apps, workers are seemingly directed by IT algorithms and software, fostering a sense that they "do not have a boss" (Steinmetz 2015). However, the platform is much more of an employer than it is a database (Aloisi 2016), but its control has become invisible. Other scholars maintain that the phrase "sharing economy" did not appear at random, but out of a business strategy (Cockayne 2016). Although platforms call their mode of operation "sharing," their apps only enable capital operation to occur between two consenting parties, whereas actual sharing never happens (Rogers 2015). In the sharing 
economy, the terms "work," "labor," "worker," and so forth are replaced by words like "share," "task," "help," "service," and so on, making workers "invisible" behind the scenes and then, gradually, the extension of IT devices, virtual platforms, and smartphone apps (De Valerio 2015).

The second line of work proceeds from workers' working preferences. Some scholars argue that working on a platform fulfills workers' psychological needs in the working process, giving them a "satisfaction" that allows them self-control (Wheatley 2017). Other than economic factors like income, many psychological considerations also push workers to participate in the platform. One group of workers may feel the need to work hard in order to get rid of negative emotions. They do not have much choice in the labor market and are drawn to platforms to avoid the emptiness, shame, or selfdepreciation associated with unemployment, and to use the skills they have learned from previous training (Murgia 2014). These individuals are willing to engage in unprotected work on platforms for the purpose of self-governance (Jiang and Wang 2017). Other workers enter platforms for the positive psychological motivations they provide (Ettlinger 2016).

The case studies analyzed in the above texts show flaws in both of these two views. The first overemphasizes platforms' control of the labor process and the covertness of Internet-based "exploitation." This view extends Burawoy's research on the labor process of large-scale industrial manufacturing, but fails to account for the fragmentation of the control of the labor process. The second view pays disproportional attention to workers' individual agency, explaining their subjective realization with their active acceptance of platforms' rules, but overlooks the factual control that platforms imposes on the labor process. Through our case study, we argue that labor control under the sharing economy has become fragmented, with labor control and work autonomy coexisting. This means that workers' subjective understanding of Internet platforms and their rules consists of both active acceptance and passive "consent" to exploitation.

\section{Data analysis and results}

According to Burawoy, workers produce more surplus value once they develop subjective "consent" in capital's control over the labor process. In the case of the platform's fragmented control and the driver's limited work autonomy, does the driver's subjective realization affect their labor supply? Since current academic research on the sharing economy and its labor is still at the beginning and discovering stage, this paper aims to investigate this question with quantitative methods in addition to the case-study method.

The data used in the following sections comes from two sources. The first is a survey of Platform W's drivers. In May 2016, with the cooperation of Platform W, we surveyed drivers using push notification on the smartphone app. To ensure representativeness, we used quota sampling, and collected 15,484 valid responses. The sample covered the nine major cities of Beijing, Chengdu, Hangzhou, Shenzhen, Hefei, Chongqing, Changsha, Shanghai, and Guangzhou. The survey asked drivers about their basic demographic characteristics, content of work, and assessment of work, among other items. The second part of our data consists of information on drivers in the sample that we pulled from Platform W's back end. 


\section{Research hypotheses}

Marx's theory of surplus value states two ways in which capitalists acquire more surplus value-forcing workers to work longer or harder to produce more absolute surplus value, and shortening the necessary labor time through technological advancement and thereby lengthening the surplus labor time and producing relative surplus value. On a sharing economy platform, capital is able to lower transaction costs and market friction through technology, largely raising speed and efficiency in matching customers with drivers. As such, following Marx, we claim that capital has increased the production of relative surplus value with technology. However, it is difficult to measure or calculate relative surplus value with the data we have collected, and therefore we do not investigate the relative surplus value that capital gains through technology. Instead, we discuss the absolute surplus value, namely drivers' working time. We measure how much drivers are controlled by the production of this absolute surplus value. Therefore, the dependent variable of our data analysis is drivers' working time.

Based on the labor process examined in the case study, drivers are impacted by the platform's payment calculation, rating system, and "autonomous and flexible" mode of working, and have developed approval of the platform's rules while being supervised by the platform. As such, our independent variables measure the platform's influence on its drivers along three axes: (1) whether or not the driver views the platform's motivation mechanism as good, (2) whether or not the driver thinks the rating system helps them to better serve customers, and (3) whether or not the driver sees work on the platform as more flexible. At the same time, we have found in the case study that the main element affecting a driver's working time on the platform is their identitywhether they drive full time or part time. Because of the considerable difference between full- and part-time drivers in terms of working time, work attitude, motivation to work, and assessment of work, we examine the two groups separately.

With the above analysis and discussion in mind, we propose two sets of hypotheses:

$\mathrm{H}_{1 \mathrm{a}}$ : Full-time drivers who approve of the platform's motivation mechanism work longer on the platform.

$\mathrm{H}_{1 \mathrm{~b}}$ : Full-time drivers who approve of the platform's rating system work longer on the platform.

$\mathrm{H}_{1 \mathrm{c}}$ : Full-time drivers who recognize platform work's flexibility work longer on the platform.

$\mathrm{H}_{2 \mathrm{a}}$ : Part-time drivers who approve of the platform's motivation mechanism work longer on the platform.

$\mathrm{H}_{2 \mathrm{~b}}$ : Part-time drivers who approve of the platform's rating system work longer on the platform.

$\mathrm{H}_{2 \mathrm{c}}$ : Part-time drivers who recognize platform work's flexibility work longer on the platform.

\section{Treatment and operationalization of variables}

1. Independent variables

We chose the following three independent variables: 
The platform's motivation mechanism as felt by the driver, turning the question "Do you think the platform's motivation mechanism is superior?" into a dummy variable that takes the value of 1 for the answer "yes" and 0 for "no."

The platform's rating system as realized by the driver, turning the question "Do you think the rating system helps you to provide more standardized service to passengers?" into a dummy variable that takes the value of 1 for the answer "yes" and 0 for "no."

The flexibility of platform work as felt by the driver: turning the question "Do you think working on the platform is more flexible?" into a dummy variable that takes the value of 1 for the answer "yes" and 0 for "no."

\section{Dependent variable}

We chose working hours to be the dependent variable. For each driver, we calculated their average weekly working hours in the ten weeks before the survey.

\section{Controlled variables}

We controlled for demographic characteristics and career variables associated with work.

Age: We subtracted the respondent's year of birth from the year the survey was conducted, 2016, to calculate the respondent's age.

Gender: We turned the respondent's reported gender into a dummy variable that takes the value of 1 for male and 0 for female.

Education attainment: We turned the respondent's highest education level into a continuous variable, which takes the value of 9 for "middle school or below," 12 for "high school or vocational high school," 16 for "college or vocational college," and 19 for "master's degree or above."

Marital status: We used the question "Are you married" to create the marital status dummy, which takes the value of 1 for the answer "yes" and 0 for "no."

Hukou status: We used the question "Is your Hukou local?" to create the Hukou status dummy, which takes the value of 1 for the answer "yes" and 0 for "no."

Number of children: We turned the answers into a continuous variable ranging from 0 to 3 .

City: We used the question "Do you live in a first-tier city?" to create a dummy variable, which takes the value of 1 for the answer "yes" and 0 for "no."

We used the difference between the time a driver finished the survey and the time they accepted their first order as their time of entering the platform to work. This is a continuous variable.

\section{Descriptive statistics of the sample}

\section{Demographic characteristics of the sample}

Based on the statistical analysis, we summarize the sample as follows. First, the average age of drivers in the sample is 35.9 , with those from 25 to 44 years old taking 
up $80 \%$ of the sample. Second, the proportion of male drivers, $95.2 \%$, is much higher than that of female drivers. Third, almost half (48.1\%) of the drivers are high school or vocational high school graduates, with $12.3 \%$ holding a college degree or above. Fourth, $84.7 \%$ of the respondents are married, and drivers in the sample have 1.3 children on average. Fifth, $65.0 \%$ of drivers in the sample do not have a local Hukou, i.e., "migrants" make up the majority of the platform's drivers. Respondents from Beijing, Shanghai, Guangzhou, and Shenzhen-the first-tier cities-make up 53.2\%, and those from other cities total $46.8 \%$.

The question "Is driving on the platform your only job?" allowed us to divide Platform W's drivers into full-time and part-time drivers. Among the 15,484 respondents, $42.24 \%$ are full-time drivers and $57.76 \%$ are part time. In comparison, parttime drivers are more educated and more likely to have a local Hukou. Demographic features of the two groups are summarized as follows. First, the two groups do not differ significantly in terms of the structure or average of age, with full-time drivers averaging 35.8 years old and part-time drivers 36.1. Second, in terms of educational attainment, $17.6 \%$ of the part-time drivers have a higher education degree (college or above), while only $5.2 \%$ of the full-time drivers do. Third, $51 \%$ of the part-time drivers have local Hukou, while the proportion of part-time drivers is only $36 \%$. Fourth, regarding family, the proportion of part-time drivers who are married is $85.5 \%$, almost two percentage points higher than that of full-time drivers, whereas full-time drivers have more children, averaging 1.37 as compared to part-time drivers' 1.24 (Table 2).

\section{Descriptive statistics of the independent variables and the dependent variable}

Descriptive statistics of the three independent variables measuring drivers' subjective approval are presented in Table 3. As shown, full-time drivers are more likely than part-time drivers to approve of the platform's rules. More specifically, the proportion of drivers who approve of the platform's motivation mechanism is $45.3 \%$ for full-time drivers and $42.3 \%$ for part-time drivers; the proportion of drivers who approve of the platform's rating system and react to their ratings is $56.9 \%$ for full-time drivers and $52.0 \%$ for part-time drivers; the proportion of drivers who recognize the flexibility of platform work is $50.3 \%$ for full-time drivers and $40.0 \%$ for part-time drivers. We included these three independent variables in a regression analysis to examine whether each group's recognition of the platform's rules led to overwork:

According to the data, the average driver works $27.2 \mathrm{~h}$ per week on the platform, but the average for full-time drivers is $37.2 \mathrm{~h}$ per week while that of part-time drivers is 20.1. In other words, full-time drivers work 1.85 times as long as part-time drivers.

\section{Regression analysis}

This paper used the time drivers worked on the platform as the dependent variable and the three aspects of drivers' recognition of the platform's rules as the independent variables to test the transformation of approval into labor supply for the two groups, controlling for demographic variables. We established the following model: 
Table 2 Demographics of full-time and part-time drivers on Platform W

\begin{tabular}{|c|c|c|c|}
\hline Variable & Category & Full-time drivers (\%) & Part-time drivers (\%) \\
\hline \multirow[t]{6}{*}{ Age (years) } & 24 or below & 5 & 3.8 \\
\hline & $25-34$ & 44.9 & 42.5 \\
\hline & $35-44$ & 33.3 & 39 \\
\hline & $45-54$ & 14.9 & 13 \\
\hline & $55-64$ & 1.9 & 1.6 \\
\hline & 65 or above & 0 & 0 \\
\hline \multirow[t]{2}{*}{ Gender } & Male & 97.5 & 97.4 \\
\hline & Female & 2.5 & 2.6 \\
\hline \multirow[t]{5}{*}{ Educational attainment } & Middle school or below & 24.2 & 11.8 \\
\hline & High school or vocational high school & 55.1 & 43 \\
\hline & Vocational college & 15.5 & 27.7 \\
\hline & College & 4.9 & 16.3 \\
\hline & Master's or above & 0.3 & 1.3 \\
\hline Marital status & Married & 83.6 & 85.5 \\
\hline \multirow[t]{4}{*}{ Number of children } & 0 & 6.1 & 7.8 \\
\hline & 1 & 55.5 & 63.3 \\
\hline & 2 & 33.6 & 26 \\
\hline & 3 or more & 4.9 & 2.9 \\
\hline \multirow[t]{2}{*}{ City } & First-tier city & 59 & 48.9 \\
\hline & Non-first-tier city & 41 & 51.1 \\
\hline \multirow[t]{2}{*}{ Hukou status } & Local & 35.9 & 51.3 \\
\hline & Not local & 64.1 & 48.7 \\
\hline
\end{tabular}

$$
Y=a_{0}+a_{1} \text { Motive }+a_{2} \text { Star }+a_{3} \text { Flex }+a_{n} X_{n}+\varepsilon
$$

in which $Y$ is the average weekly working hours of the driver in the most recent 10 weeks. Motive is the dummy variable indicating whether the driver views the platform's motivation mechanism as good. Star is the dummy variable indicating whether the driver thinks the rating system helps them better serve customers. Flex is the dummy variable indicating whether the driver believes working on the platform is flexible. $X_{n}$ is the demographic variable that includes time in the industry, age, gender, years of education, marital status, Hukou status, number of children, and city. $\varepsilon$ is the error term.

We used Stata to carry out stepwise regression on the above model, so that variables that can cause multicollinearity are filtered out and eliminated, and the result is the most optimum.

\section{Regression results: full-time drivers}

The results of the above regression model for the full-time driver group, controlling for other variables, are presented in Table 4. The following results are noteworthy.

First, full-time drivers who approve of the platform's motivation mechanism appear to supply more labor time. Compared to those who do not approve of the mechanism, they work 2.7 more hours each week on average. Full-time drivers who believe the rating system changed their work behavior also appear to supply more labor time. 
Table 3 Descriptive statistics of subjective approval

\begin{tabular}{|c|c|c|c|c|c|c|}
\hline \multirow[t]{2}{*}{ Percentage (\%) } & \multicolumn{2}{|c|}{$\begin{array}{l}\text { Platform's motivational } \\
\text { mechanism is good }\end{array}$} & \multicolumn{2}{|c|}{$\begin{array}{l}\text { Rating system standardizes } \\
\text { my service to passengers }\end{array}$} & \multicolumn{2}{|c|}{$\begin{array}{l}\text { Platform work is } \\
\text { more flexible }\end{array}$} \\
\hline & Yes & No & Yes & No & Yes & No \\
\hline Full-time drivers & 45.3 & 54.7 & 56.9 & 43.1 & 50.3 & 49.7 \\
\hline Part-time drivers & 42.3 & 57.7 & 52.0 & 48.0 & 40.0 & 60.0 \\
\hline
\end{tabular}

Compared to those who think otherwise, they work 1.3 more hours each week on average. Although half of the full-time drivers think platform work is flexible, the corresponding explanatory variable is excluded from the final regression equation due to insignificance.

Second, when looking at other controlled variables, male full-time drivers work 4.8 more hours on average than female full-time drivers each week; those in first-tier cities work 1.7 more hours than their counterparts in other cities; those with local Hukou work 10.7 fewer hours each week than those without. The effects of time in the industry, age, education, and number of children are significant but small in size.

Third, the VIF test shows no collinearity among independent variables.

2. Regression results: part-time drivers

Results of the above regression model for the part-time driver group, controlling for other variables, are presented in Table 5. The following results are noteworthy.

First, part-time drivers who believe that working on the platform is flexible work more hours. Compared to drivers who do not believe in this flexibility, they work one more hour on average each week. Recognition of either the motivation mechanism or the rating system does not have significant effect on part-time drivers' working time.

Second, drivers with non-local Hukou work 4.5 more hours on average than those with local Hukou, whereas drivers in first-tier cities work 2.5 more hours weekly than their peers in other cities. Years of education and age also have significant effects on part-time drivers' working time, but at a lower level. Other controlled variables are not significant enough to be included in the final model.

Table 4 Regression results: full-time drivers $N=5335$

\begin{tabular}{ll}
\hline Variable & Regression coefficient \\
\hline Motivation mechanism is good (reference category: yes) & $2.666^{* * *}(.582)$ \\
Rating standardizes my service (reference category: yes) & $1.313^{* *}(.588)$ \\
Time in the industry & $.0108^{* * *}(.00236)$ \\
Age & $.278^{* * *}(.0389)$ \\
Gender (reference category: male) & $4.838^{* *}(1.913)$ \\
Year of education & $-.586^{* * *}(.127)$ \\
Hukou status (reference category: local) & $-10.71^{* *}(.665)$ \\
Number of children & $.341^{* *}(.146)$ \\
City (reference category: first-tier cities) & $1.678^{* * *}(.609)$ \\
Constant & $29.27^{* * *}(2.854)$ \\
$R^{2}$ & 0.087
\end{tabular}

Based on the regression results, only significant independent variables are presented here. The same applies to Table 5 ${ }^{*} p<0.1 ;{ }^{* *} p<0.05 ;{ }^{* * *} p<0.01$ 
Table 5 Regression results: part-time drivers $N=7121$

\begin{tabular}{ll}
\hline Variable & Regression coefficient \\
\hline Work is flexible (reference category: yes) & $.978^{* *}(.393)$ \\
Year of education & $-.605^{* * *}(.0796)$ \\
Hukou status (reference category: local) & $-4.461^{* * *}(.427)$ \\
Time in the industry & $.00875^{* * *}(.00158)$ \\
Age & $.278^{* * *}(.026)$ \\
City (reference category: first-tier cities) & $12.529^{* * *}(.402)$ \\
Constant & $18.43^{* * *}(1.464)$ \\
$R^{2}$ & .065 \\
\hline
\end{tabular}

${ }^{*} p<0.1 ;{ }^{* *} p<0.05 ;{ }^{* * *} p<0.01$

Third, the VIF test shows no collinearity among independent variables.

\section{Brief summary}

Through stepwise regression, we tested the two sets of hypotheses formulated previously. In the first set, $\mathrm{H} 1 \mathrm{a}$ and $\mathrm{H} 1 \mathrm{~b}$ are supported but not H1c. In the second set, neither $\mathrm{H} 2 \mathrm{a}$ nor $\mathrm{H} 2 \mathrm{~b}$ is supported, but $\mathrm{H} 2 \mathrm{c}$ is supported. Interpreting these results, we can conclude that full-time drivers who approve of either the platform's motivational mechanism or its rating system work more hours, but recognition of work flexibility does not change full-time drivers work time, despite the fact that half of them believe platform work is more flexible. The case of part-time drivers, however, is entirely different. The recognition of flexibility significantly raises the drivers' labor while that of either the motivation mechanism or the rating system does not alter their working time. In other words, the platform stimulates cooperation from its drivers by inducing recognition and satisfaction, and in this mechanism motivation and rating stimulates labor time from fulltime drivers while flexibility stimulates labor time from part-time drivers.

\section{Conclusion and discussion}

Using mixed-method analysis, this paper studies work control, workers' agency, and labor supply through an in-depth investigation on the labor process of workers on Platform W. Our study differs from previous work in the following three aspects.

First, our work applies and extends Marxist labor-process theory to the contemporary world. After Marx, scholars like Braverman, Edwards, Friedman, and Burawoy have contributed tremendously to the extension of labor-process theory. Under the present new business models and employment circumstances, study of the labor process is still crucially meaningful. We turn the research focus to a flexible employment form and specifically emphasize workers' agency.

Second, this work contributes to academic research on the sharing economy. The sharing economy has just started to unfold, and most academic research is still at the beginning stage. Most of it is exploratory work focusing on the definition and typology of the sharing economy, while comprehensive descriptive analysis and in-depth explanatory analysis are lacking. This paper pays special attention to new features of work under the sharing economy, and reveals the difference of current labor process control and workers' agency from those in the era of large-scale industrial manufacturing. 
Third, in terms of research methodology, our mixed-method approach, which enables a complicated discussion of the labor process in the sharing economy and combines case study and statistical analysis, is an augmentation to this field of study.

Through this mixed-method study, we have found that the sharing economy relies on Internet platforms and technology, at once fragmenting work tasks and labor control. Therefore under the sharing economy employment model, fragmented control coexists with workers' work autonomy. This new mode of employment also complicates workers' subjective realization and experience about platforms and their rules. Such subjective realization that results from the combination of active approval and passive acceptance is far more complicated than the "consent" that Burawoy describes.

Although workers enjoy a certain degree of work autonomy, platforms hold stronger and more-covert control over workers' online working process. Through motivational payment systems and task designs, workers are unknowingly integrated into the game and finish or even exceed their task targets. At the same time, the star rating system allows platforms to utilize consumers' supervision to obtain de facto control over the time, form, and environment of workers' work, as well as to use practices resembling an employer's sanction. With the design of these motivation mechanisms, rating system, supervising system, and so on, platforms obtain de facto control over the labor process, generating more approval than grievances and more cooperation than resistance among workers, and thereby reproducing capital.

\section{Endnotes}

${ }^{1}$ For more information on this, see the verdict of United States Court of Appeals for the Seventh Circuit (Nos. 16-2009, -2077, and -2980, http://caselaw. findlaw. com/ us-7th-circuit/1750600. html), written by Posner and colleagues (2016). Posner's explanation and assessment of the competition between online car hailing and traditional taxi service led to intensive debate.

${ }^{2}$ For discussions on this topic, see Harris and Krueger 2015; Aloisi 2016; Kennedy 2016; Kurin 2017; Campbell and Price 2016; Minter 2017; Chang 2016; Wang 2016; Katz and Krueger 2016.

${ }^{3}$ In Labor and Monopoly of Labor, Braverman writes: "No attempt will be made to deal with the modern working class on the level of its consciousness, organization, or activities. This is a book about the working class as a class in itself, not as a class for itself" $(1979,29)$.

Acknowledgements

The authors are grateful for comments from the reviewers.

Authors' contributions

The two authors equally share the workload of data collection and writing. Both authors read and approved the final manuscript.

Funding

This paper supported by the Fundamental Research Funds for the Central Universities, and the Research Funds of Renmin University of China (14XNQ012). 


\section{Author details}

${ }^{1}$ School of Labor and Human Resources, Renmin University of China, No. 59 Zhongguancun Street, Haidian District, Beijing 100872, People's Republic of China. ${ }^{2}$ China Central Television, CCTV, No. 1 Guanhua Street, Chaoyang District, Beijing 100020, People's Republic of China.

Received: 21 March 2019 Accepted: 5 June 2019

Published online: 23 July 2019

\section{References}

Aloisi, A. 2016. Commoditized workers: Case study research on labor law issues arising from a set of "on-demand/gig economy" platforms. Comparative Labor Law and Policy Journal 37 (3): 620-653.

Braverman, H. 1974. Labor and monopoly capital: The degradation of work in the twentieth century. New York: Monthly Review Press.

Brown, G.E. 2016. An Uber dilemma: Employees and independent contractors in the sharing economy. Labor and Employment Law 75 (15): 14-43.

Burawoy, M. 1979. Manufacturing consent: Changes in the labor process under monopoly capitalism. Chicago: University of Chicago Press.

Burawoy, M. 2008. In Manufacturing consent, trans, ed. R. Li et al. Beijing: Commercial Press.

Campbell I. and R. Price. 2016. Precarious Work and Precarious Workers: Towards an Improved Conceptualisation. Economic and Labour Relations Review 27 (3): 314-332.

Cao, J., and Nanhua Zhang. 2012. New media, knowledge labor and flexible working with interest: A case study of the fan subbing Group in Mainland China. Journal and Communication 5: 39-47.

Cappelli, P., and J.R. Keller. 2013. Classifying work in the new economy. Academy of Management Review 38 (4): $575-596$. Chang, K. 2016. Employment or cooperation, what is the working relation of the sharing economy. Human Resource 11: 38-40

Chen E. 2015. Order Denying Defendant Uber Technologies, INC.'S Motion for Summary Judgment. No. C-13-3826 EMC, https://www.pdffiller.com/236551532-OConnor-v-Uber-Technologiespdf-ORDER-DENYING-DEFENDANT-UBERTECHNOLOGIES-INCS-MOTION-FOR-Various-Fillable-Forms.

Cockayne, D. 2016. Sharing and neoliberal discourse: The economic function of sharing in the digital on-demand economy. Geoforum 77: 73-82.

Cunningham-Parmeter, K. 2016. From Amazon to Uber: Defining employment in the modern economy. Boston University Law Review 96: 1673-1728.

Edwards, R. 1981. Contested terrain: The transformation of the workplace in the twentieth century. Administrative Science Quarterly 2 (5): 54-56.

Elger, T. 1979. Valorisation and "deskilling": A critique of Braverman. Capital \& Class 7 (1): 58-99.

Ettlinger, N. 2016. The governance of crowdsourcing: Rationalities of the new exploitation. Environment \& Planning A 48 (11): 2162-2180.

Farrell, D. and Greig, F. 2016. Paychecks, Paydays and the Online Platform Economy: Big Data on Income Volatility. JPMorgan Chase \& Co. Institute Working Paper.

Finkin, M. 2016. Beclouded work, beclouded Workers in Historical Perspective. Comparative Labor Law \& Policy Journal 37: 578-603.

Friedman, A.L. 1977. Industry and labor: Class struggle at work and monopoly capitalism. London and Basingstoke: Macmillan Press.

Hall J. and A. Krueger. 2018. An Analysis of the Labor Market for Uber's Driver-Partners in the United States. Industrial \& labor Relations Review 71 (3): 705-732.

Harris, S.D. and Krueger, A. 2015. A Proposal for Modernizing Labor Laws for Twenty-First-Century Work: The "Independent Worker." The Hamilton Project Discussion Paper, No. 2015-10.

Jiang, D., and Shoujie Wang. 2017. Legal rules of the sharing economy. Social Sciences in China 9: 141-162.

Katz L. and Krueger, A. 2016. The Rise and Nature of Alternative Work Arrangements in the United States, 1995-2015. National Bureau of Economic Research Working Papers, No. 22667.

Kennedy J. 2016. Three Paths to Update Labor Law for the Gig Economy. Working Paper, http://www2.tifi.org/2016-labor-lawgig-economy.pdf.

Kurin J. 2017. A Third Way for Applying U.S. Labor Laws to the Online Gig Economy: Using the Franchise Business Model to Regulate Gig Workers. Journal of Business \& Technology Law 12 (2): 193-226.

Li, Y., and Quanxing Wang. 2016. Legal protection of autonomous labor under flexible employment in China. Southeast Academic Research 3: 104-113.

Marx, K. 2004. The capital, trans. Central Compilation \& Translation Bureau. Beijing: People's Press.

Minter K. 2017. Negotiating Labour Standards in the Gig Economy: Airtasker and Unions New South Wales. Economic and Labour Relations Review 28 (3): 438-454

Murgia A. 2014. Representations of Precarity in Italy. Journal of Cultural Economy 7 (1): 48-63.

Prassel J. and M. Risak. 2016. Uber, Taskrabbit, \& Co: Platforms as Employers? Rethinking the Legal Analysis of Crowdwork. Comparative Labor Law \& Policy Journal(Forthcoming), https://papers.ssrn.com/sol3/papers.cfm?abstract_id= $2733003 \&$ rec $=1 \&$ srcabs $=2641305 \&$ alg $=1 \&$ pos $=4$

Rogers, B. 2015. The Social Costs of Uber. Temple University Legal Studies Research Paper No. 2015-28.

Rosenblat, A. 2016. What motivates gig economy workers. Harvard Business Review 17: 2-5.

Rosenblat, A., and L. Stark. 2016. Algorithmic labor and information asymmetries: A case study of Uber's drivers. International Journal of Communication 10: 3758-3784.

Stanford J. 2017. The Resurgence of Gig Work: Historical and Theoretical Perspectives. Economic and Labour Relations Review 28 (3): $382-401$

Steinmetz, K. 2015. Is the on-demand economy taking Workers for a Ride? Time 186 (5): 11-15.

Valerio De S. 2015. The Rise of the "Just-in-Time Workforce": On-Demand Work, Crowdwork and Labor Protection in the "GigEconomy". Working Paper, http://www.ilo.org/public/libdoc/ilo/2016/116B09_2_engl.pdf.

Wang, T. 2016b. Determining employment relations for work on online platforms - E-daijia's judicial cases in Beijing, Shanghai, and Guangzhou. Law Studies 2016 (6): 50-60. 
Wen, X., and Xiao Zhou. 2007. The Western labor process theory and the Chinese experience: A critical review. Social Sciences in China 3: 29-39.

Wheatley D. 2017. Employee Satisfaction and Use of Flexible Working Arrangements. Work, Employment and Society 31 (4): $567-585$.

You, Z. 2006. Managerial control and workers resistance: A review of literature on the capitalist labor process. Sociological Studies 4: 169-185.

\section{Publisher's Note}

Springer Nature remains neutral with regard to jurisdictional claims in published maps and institutional affiliations.

Submit your manuscript to a SpringerOpen ${ }^{\odot}$ journal and benefit from:

- Convenient online submission

- Rigorous peer review

- Open access: articles freely available online

High visibility within the field

- Retaining the copyright to your article

Submit your next manuscript at $\boldsymbol{\nabla}$ springeropen.com 